\title{
Pondering Deeper onto Threshold Concepts in Engineering: A Case of Mathematical Modelling
}

\author{
Thobeka Pearl Makhathini \\ Department of Chemical Engineering, Mangosuthu University of Technology, South Africa
}

\begin{abstract}
Teaching mathematics in South Africa continues to follow traditional pedagogy. Even though traditional pedagogy has satisfactory benefits, it is well understood that it does not effectively prepare students to perform well in Higher Education applied mathematics concepts. Moreover, traditional pedagogy seems to train students to answer questions not necessarily to solve problems through the application of knowledge. Evidently, there is less capacity to deal with open-ended problems, which is a fundamental feature for mathematical modelling formulation. This paper argues that the incapacity to handle open-ended problems is the key shortfall resulting in many deep challenges experienced by chemical engineering students. An assessment was conducted to understand the challenges facing the final year chemical engineering students doing a process control module which requires the formulation of a mathematical model using first-order differential equations. Students completed an assessment survey which measures their understanding and examines the ability to approach open-ended problems, to implore their perspectives of the module and their anticipations of the lecturer. The study found that chemical engineering students are battling to translate process related problem statements to mathematical expressions.
\end{abstract}

\section{Introduction}

South Africa is a hierarchical society in an economically developing country where hierarchy is measured by the difference between low income community and the wealthy community. A vast majority of the population lives in typical low-income threshold in contrast to the promises made by the democratic government post-apartheid era [1]. In the midst of this crisis, the unemployment rate continues to rise, and South Africa needs a real growth in its GDP of $6.2 \%$ by year 2020 to rectify this dire situation (Trading Economics 2018). At the moment South African government is encouraging youth to start thinking differently, to not wait for minimal opportunities to be employed but rather create employment themselves through innovation of small businesses. One of the challenges for the youth is their ability to think further than the classroom, so as to develop epistemic virtues. It is well articulated that epistemic virtues can be developed through STEM field subjects, this includes mathematics.

Furthermore, [2] emphasizes that with evolving technological economic world, the only way to keep abreast in this global competition is through mathematics performance. Mathematics performance in a South African context could be influenced by more than one factor, amongst many are, class sizes, language of instruction and socio-economic status. Having said this, there is a persistent challenge in mathematics education among the low-income community students which is indeed a worry because mathematical articulation is considered a necessary knowledge and attribute in a highly competitive worldwide economy. Amongst many reasons owing to the challenges in mathematics learning are poor school policies, unstructured curricula and teaching methods that are not aligned to the context of the students. These challenges which are more eminent in basic education sector overlaps and spill over to the higher education sector, which strains the university resources in trying to close the articulation gap. These challenges are well documented by Akoojee and Nkomo [3] where they highlight the under preparedness of the students coming from basic education into university.

This paper concurs with Howie [4] that when the 'learning and teaching' language is not the same as home language, challenges with grasping concepts are expected. The issue of the language of learning seem to be put students in difficult situation where they are expected to solve open-ended questions in mathematics or application thereof. In engineering education, students are expected to solve complex worded problem through application of physics and mathematics 
principles. Regrettably, mathematics is viewed by many as a closed subject which consists of formulae only. As such this view is clear when students are required to describe process operations in chemical engineering course using mathematical modelling. Hence this paper aims to investigate the difficulties encountered by the final year chemical engineering students when dealing with open ended problems and their attitude towards these types of questions.

\section{Theoretical Framework}

This paper draws on theoretical frameworks of curriculum and pedagogy responsiveness as a concept, but mainly draws on cultural responsiveness pedagogy. This concept is better explained by Moll [5], saying they can triangulate as learning, disciplinary and cultural responsiveness. This theory is important as it endeavors positively formulated benchmarks against which may assist to judge the education programs whether they meet the needs of a transforming society [6]. Without a doubt, for many years the dominant teaching practice in mathematics for students from low-income communities has formulated a trend of a traditional approach that is established on narrow thinking. Mainly focusing of either a right or a wrong answer, not considering the thinking approach to solve the given problem. Of course, this practice in mathematics learning and teaching do not meet the problem-solving style expected at the university level and beyond. Furthermore, these practices enhance an environment where students are less motivated and little to no success is achieved in mathematics learning [7].

\subsection{Teaching practice}

In the sphere of teaching practice, there are three prevalent themes in the published literature: academic literacy of the discipline, engagement of students in more active ways whilst developing conceptual understanding [8]. One of the best teaching practices in engineering and mathematics is centralized around active learning [9]. Moreover, many researchers emphasize the importance for development of conceptual understanding [10]. The 'English language proficiency' comes up where the students are mainly using it as a second language. Without a doubt, the English language proficiency brings about challenges in the classroom, especially for the students from lowincome communities. The university teacher has an obligation to make the disciplinary discourse explicit to create an enabling environment for the students. This objective is not always achieved because of the lack of proper language understanding from the student's side. As suggested by Jacobs [11] an employment of 'collaborative pedagogy' may assist the lecturers to achieve their objective. The lecturers may use graphics and symbols to assist students with internalizing the new concepts in engineering discipline, rather than loads of text. Newly developed teaching approaches are essential to support students' learning.

\subsection{Curriculum and cultural responsiveness}

The curriculum alignment is better articulated by informed educational approaches in most literature. Some research highlight the importance of considering the knowledge structure in curriculum design [12], especially in engineering context, problem-based learning must be in the center. This paper reiterates the views of Case [8] that lecturers need to meet the students capabilities. Also, in international context, the literature that is STEM focused concur that lecturers need to teach learners they have (from high school), not only those they wish wished for [13]. Lately there has been more emphasis on focusing on employability of students, where graduate attributes are deemed as a necessary outcome in the learning cycle [14].

\section{Description of the module}

There are 110 final year students enrolled for this module every semester in the department of chemical engineering at Mangosuthu University of Technology (MUT). Since they are in the final year, it is assumed that they have mastered mathematical concepts in Mathematics I offered in first year, and also Mathematics II offered in second year. It happens rarely that students will come from other institutions of higher learning to only complete their final year at MUT. Evidently, in these Mathematics modules they are often taught to answer direct problems, however they have limited contact to 'open ended' problems, where they have to think further than 'solve for $x$ '. As such students were not trained to develop problem solving techniques, without being told directly what to solve. Many of these students came from low-income family background, where their learning preparation of mathematics was of less demanding nature.

In this course, students are required to demonstrate their understanding of engineering processes using mathematical equations. Mathematical equations include first order differential equations, linear algebra, systems of linear first-order equations and models involving higher order differential equations. The main objective of the course is to give exposure to students into real life process challenges, to simulate process plant functions and to indoctrinate some modelling skills in students. It is normally expected that the students are be able to translate the engineering process situation to a useful mathematical model, solve the model, synthesize and analyze the results thereafter back to the 
engineering process scenario. This is the practice, which is important for the workplace, hence students are required to develop this knowledge skill for future.

\section{Research Method}

At the beginning of the modelling section in process control module, students were given questionnaires to complete. In these questionnaires there were two worded engineering process problems to assess their thinking of non-routine problems. Also, in part two of the questionnaire, we attempted to solicit students 'views of the module and their expectations of the lecturer.

The layout of the questionnaire was as follows: a. Consider the figure 1 below where Tank 1 has $30 \mathrm{~m}^{3}$ of water containing $55 \mathrm{~kg}$ of dissolved salt, and Tank 2 has $20 \mathrm{~m}^{3}$ of water containing $26 \mathrm{~kg}$ of dissolved salt. Water with salt concentration of $1 \mathrm{~kg} / \mathrm{m}^{3}$ flows into Tank 1 at a rate of $1.5 \mathrm{~m}^{3} / \mathrm{min}$. Water with salt concentration of $3 \mathrm{~kg} / \mathrm{m}^{3}$ flows into Tank 2 at a rate of $1 \mathrm{~m}^{3} / \mathrm{min}$.

A large tank holds 200 gallons of brine solution with 40 pounds mass of salt. A concentration of $2 \mathrm{lb} / \mathrm{gal}$ is pumped in a constant rate of $4 \mathrm{gal} / \mathrm{min}$. The concentration leaving the tank is pumped out at the same rate as the inlet rate. How much salt is in the tank after 1 hour?

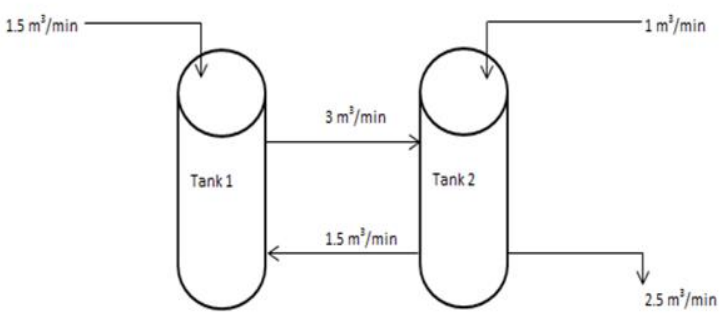

Figure 1. Tank 1 and 2 with dissolved salts where students were asked to: derive the equations $\mathrm{M}_{1}(\mathrm{t})$ and $\mathrm{M}_{2}(\mathrm{t})$ leading to the amount of salt in Tank 1 and 2

The selection of both questions is aligned to the challenging areas that we want to examine (translation of the authentic process problem to mathematical representation). In both of these questions the differential equations were not given directly but students needed to formulate these themselves, using prior knowledge from second year Mathematics II module. The problems were deemed relatable to students because the solution of salt and water is something they have experience on in real life. In both these cases, we hoped that students will use a scaffolding methodology to build from prior knowledge of basic principles and make knowledge links to solve these problems.
An open call to participate in the survey (as question (c)) was made to the students after they took the test; about 63 students responded. All the responses from the students were collated and sorted into different sets. As such a qualitative analysis was performed on the responses, not limited to the difficulties and errors made, together with their views.

\section{Discussion of the results}

This section gives student's responses in parts according to the two given problems:

In attempting the first problems (a), more than half of the students showed understanding of what Tank 1 and Tank 2 was meant to do, however renaming of the input and output streams proved to be difficult for them, as some couldn't differentiate between a mass or volumetric flowrate. Hence the subsequent equations were off the mark on most students. Even though most quantities were given on this problem, students were unable to figure out that each stream was to be multiplied by concentration in order to convert the volumetric flow to mass flowrate. This is a huge flaw because the differential equation they needed to derive is for the accumulation of mass per time in both Tank 1 $\frac{d M_{1}}{d t}$ and Tank $2 \frac{d M_{2}}{d t}$. Only $10 \%$ of the students were able to even have these equations at towards the end of their mathematical models, but there was difficulty in showing how they arrived at the final equations. There seem to be no particular approach that they followed to solve the problem.

In attempting the second problem, it was found that more than $70 \%$ of the students did draw a diagram to further understand the problem, this was deemed as an excellent approach towards solving problems. However, the rest of the students went straight into solving the problem without getting a meaningful understanding of which variables are given, and what exactly are they asked to do in this problem. Again, there was no evidence of structured approach towards solving the given problems. The study recorded less than $15 \%$ students were able to comprehend the quantity $\rho$ can be found using quantity $M$ and $V$ of the tank with brine solution.

Most students understood $\rho$ as an unknown variable, when in fact it is a known variable. In overall, students struggled with identification of known and unknown variables. Since in this problem, after formulating a differential equation, students were to solve the equation to find the quantity of mass in the brine after an hour. For $M(t)$ to be found, students needed to further integrate the ordinary differential equation (ODE), they could use any techniques they deemed fit. The ODE could be solved using integrating factor or integrating by parts. Interestingly, a few students who managed to get 
the ODE correctly, were unable to choose the relevant integrating approach towards finding $M(t)$.

Formulation of the relevant equations to both problems was identified by only eleven students out of the cohort of 63 students, although the second problem was not completed by all students. Though the drawing was given in the first problem which was supposedly made the understanding of the problem much easier, students still struggled to formulate mathematical statements. It seems like students do not have an appropriate understanding of the mathematics concepts they learnt in prior levels of study. The main difficulty faced by most students in both problems were: average level of English language (especially in the second problem), application of mathematical understanding and difficult in logical reasoning or thinking. The mathematics lecturer in level 1 and 2 of the courses believed that students could easily solve both these problems because he taught the concepts required to solve the problems.

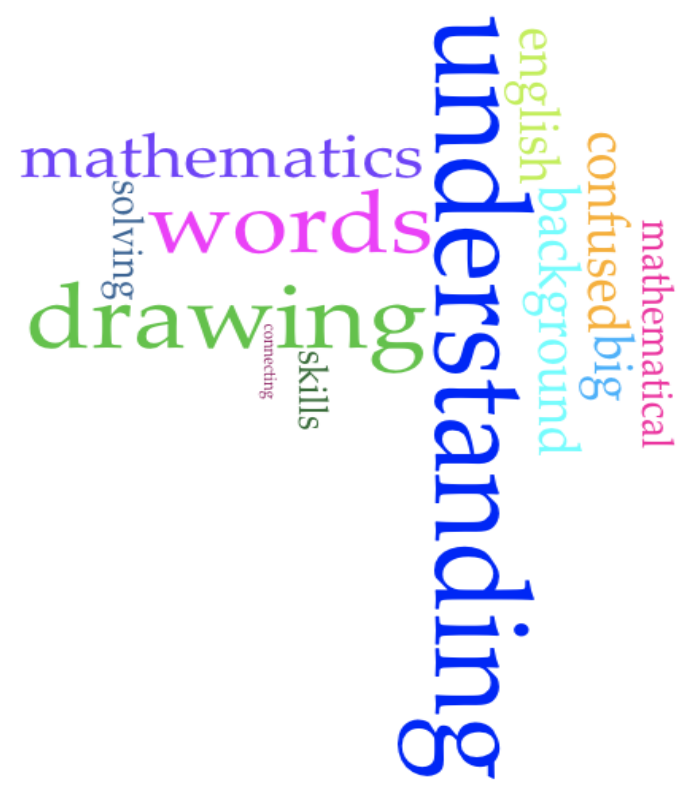

Figure 2. A graphic representation of students' views on the challenges they encountered in development of mathematical models

The last part of the questionnaire with question (c), which seeks to determines students' outlook towards the course at final year of study. Most students shared that they did not understand what 'brine solution' is from problem (b), as a result they were confused about developing a model that describes the amount of salt in the tank. From problem (a), they appreciated that the drawing was given but still they could not understand how they were supposed to get some parameters i.e. density in Tank 1 or Tank 2. Students highlighted that lecturers do not consider their background regarding the English language, hence they use 'big words' in problem statements which they cannot interpret. Apart from the language barrier, students are unable to connect what they learnt in mathematics level 1 and 2 modules with the knowledge presented in the final year. Unexpectedly, more than $65 \%$ of students anticipated that they will do very well in this engineering module due to high marks obtained in previous mathematics modules.

Most of the response from students mentioned similar challenges, as illustrated in figure 2 . The main challenge that was repeatedly mentioned by most students in the 'understanding' of the question. They also mentioned that there was some English language 'words' that they were not familiar with. Moreover, they highlighted that the lack of the graphical representation was a challenge together the lack of mathematical skills. This aspect was unexpected since the students had already done the level 1 and 2 Mathematics. The responses also give an insight to their lack of background theory on mathematical expressions.

Furthermore, students were required to do selfassessment after they had written the exercise. Students mention broadly that assessments from previous levels of study did not require them to understand the process first. They mentioned that they rely strongly on their peers for information and they deem their relationship with their peers valuable. They mentioned lack of motivation to do well after knowing that what they thought they knew is not really useful in this class. Students seem to be disappointed with the fact that they are unable to use a scaffolding methodology to build on the knowledge they already have from previous subjects.

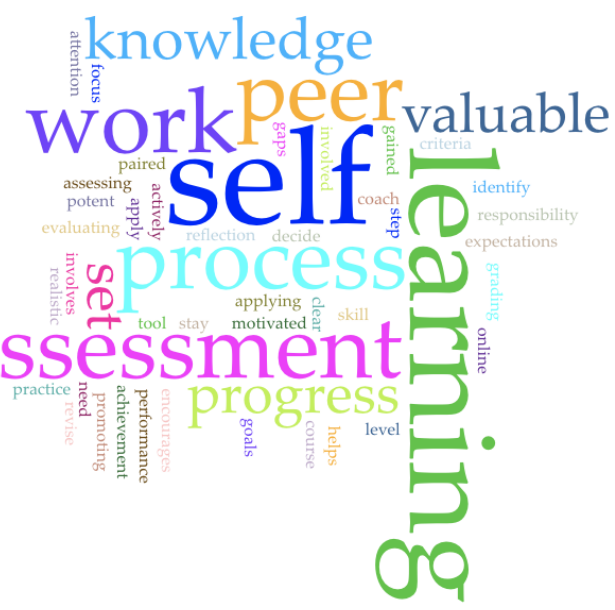

Figure 3. A graphical representation of the students' views on self-assessment 


\section{Conclusions}

The paper identified key challenge with the classification of process variables whether as dependent or independent, input or output quantities. In such a case, it becomes extremely difficult to formulate mathematical models. Students seemed to lack a structured approach in attempting open ended problems including mathematical model context. A recommended approach to solve the modelling problems is given in figure 3 below. This step-by-step approach is aligned to the constructivist learning theory, which advocates for learners constructing their own understanding. Having said this, the approach proposed in figure 4 can only be used a guide in order to assist the students to have the frames of reference.

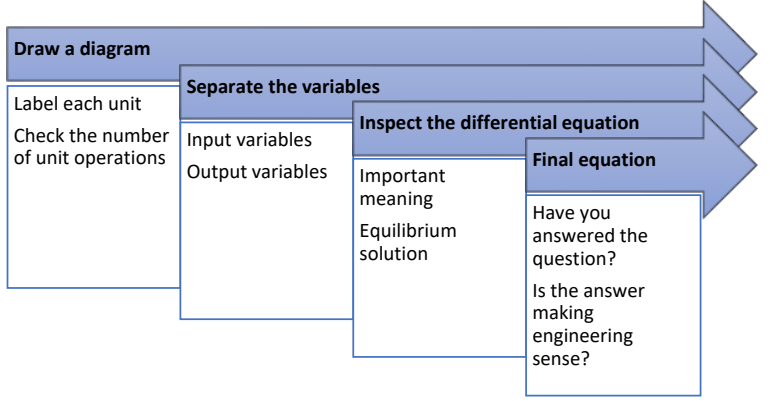

Figure 4. A proposed step-by-step approach towards development of a mathematical model

In conclusions, students believe that high results obtained in previous modules are a demonstration of the knowledge students possess for particular concepts. An inaccurate self-assessment of students is worrying because they are unable to seek assistance early in the year because of the belief that they are well vested with mathematics concepts. From the findings in this study, it is recommended that lecturers at final year level of study assists students with step-by-step approach towards solving complex problems, rather than assuming that students have learnt this knowledge in prior levels of their study.

\section{Acknowledgements}

The author would like to thank Teaching and Learning Development Centre of Mangosuthu University of Technology for their support.

\section{References}

[1] Y. Sayed and R. Ahmed, "Education quality in post- 35, 1990.

apartheid South African policy: balancing equity, diversity, rights and participation," Comp. Educ., vol. 47, no. 1, pp. [14] T. P. Makhathini, "Work integrated learning 103-118, 2011.
[2] A. P. Carnevale, "Education and the economy: If we're so dumb, why are we so rich," Educ. Week, vol. 24, no. 21, pp. 40-41, 2005.

[3] S. Akoojee and M. Nkomo, "Access and quality in South African higher education: The twin challenges of transformation," South African J. High. Educ., vol. 21, no. 3, pp. 385-399, 2007.

[4] S. J. Howie, "Language and other background factors affecting secondary pupils' performance in Mathematics in South Africa," African J. Res. Math. Sci. Technol. Educ., vol. 7, no. 1, pp. 1-20, 2003.

[5] I. Moll, "Curriculum responsiveness: The anatomy of a concept," Curric. responsiveness Case Stud. High. Educ., pp. $1-19,2004$.

[6] O. N. Ukpokodu, "How do I teach mathematics in a culturally responsive way?: Identifying empowering teaching practices.," Multicult. Educ., vol. 19, no. 3, pp. 47$56,2011$.

[7] W. F. Tate, "Returning to the root: A culturally relevant approach to mathematics pedagogy," Theory Pract., vol. 34, no. 3, pp. 166-173, 1995.

[8] J. Case, D. Marshall, and D. Grayson, "Mind the gap: Science and engineering education at the secondary-tertiary interface,” S. Afr. J. Sci., vol. 109, no. 7-8, pp. 1-5, 2013.

[9] C. Winberg, "Teaching engineering/engineering teaching: interdisciplinary collaboration and the construction of academic identities," Teach. High. Educ., vol. 13, no. 3, pp. 353-367, 2008.

[10] I. Scott, "First-year experience as terrain of failure or platform for development? Critical choices for higher education," Focus first-year success Perspect. Emerg. from South Africa beyond, pp. 17-36, 2009.

[11] C. Jacobs, "Towards a critical understanding of the teaching of discipline-specific academic literacies: Making the tacit explicit," J. Educ., vol. 41, no. 1, pp. 59-81, 2007.

[12] J. Case, "Knowledge matters: interrogating the curriculum debate in engineering using the sociology of knowledge," J. Educ., vol. 51, no. 2, pp. 1-20, 2011.

[13] D. H. Clements and M. T. Battista, "Constructivist learning and teaching," Arith. Teach., vol. 38, no. 1, pp. 34competencies: Industrial supervisors' perspectives," Perspect. Educ., vol. 34, no. 3, pp. 56-71, 2016. 